\title{
As evidencialidades de raciocínio e sua combinação com tempo e modo no português brasileiro
}

DOI: http://dx.doi.org/10.21165/el.v50i3.2909

\author{
Vítor Henrique Santos da Silva'
}

\section{Resumo}

Analisando orações complexas em que a matriz é nucleada pelos verbos inferir, deduzir, concluir, perceber, observar e ver, este trabalho objetiva testar a hipótese de que, se esses verbos expressam inferência ou dedução, subtipos evidenciais de acordo com Hengeveld e Hattnher (2015), o tempo e o modo da encaixada é diferente a depender do subtipo. Os resultados comprovam essa hipótese, já que, nos dados analisados, a encaixada com a informação deduzida só se apresenta em tempos do passado e do presente do indicativo, enquanto a informação inferida ocorre nos tempos presente, passado e futuro e nos modos indicativo, subjuntivo e condicional. As ocorrências provêm do Corpus Brasileiro (SARDINHA; MOREIRA FILHO; ALAMBERT, 2010) e do Timestamped JSI web corpus 20142020 (TRAMPUS; NOVAK, 2012), e são analisadas com o auxílio do Goldvarb X (SANKOFF; TAGLIAMONTE; SMITH, 2005).

Palavras-chave: evidencialidade; inferência; dedução; raciocínio; Gramática DiscursivoFuncional.

1 Universidade Estadual Paulista "Júlio de Mesquita Filho" (UNESP), São José do Rio Preto, São Paulo, Brasil; vitorhss20@gmail.com; https://orcid.org/0000-0003-4649-2170 


\title{
Evidentiality of reasoning and their combination with tense and mood in Brazilian Portuguese
}

\begin{abstract}
Analyzing complex clauses in which the head of the matrix are the verbs inferir, deduzir, concluir, perceber, observar, and ver, I test the hypothesis that, if these verbs express inference or deduction, evidential subtypes as stated by Hengeveld and Hattnher (2015), tense and mood of the embedded clause is different according to the subtype expressed. The results confirm this hypothesis since, in the analyzed data, the embedded clause with the deduced information is restricted to past and present tenses of the indicative mood, whereas the inferred information occurs in present, past, and future tenses and in indicative, subjunctive, and conditional moods. The occurrences pertain to Corpus Brasileiro (SARDINHA; MOREIRA FILHO; ALAMBERT, 2010) and Timestamped JSI web corpus 2014-2020 (TRAMPUS; NOVAK, 2012), and are analyzed with the assistance of Goldvarb X (SANKOFF; TAGLIAMONTE; SMITH, 2005).
\end{abstract}

Keywords: evidentiality; inference; deduction; reasoning; Functional Discourse-Grammar.

\section{Introdução}

O estudo sobre a expressão lexical da evidencialidade ou, nos termos de Aikhenvald (2004), das estratégias de evidencialidade², tem ganhado espaço nos últimos anos. Isso se deve, sobretudo, pela tentativa de se entender como a fonte da informação é marcada em línguas que não dispõem de meios gramaticais para veicular tal função.

Nesse panorama, definindo a evidencialidade como a indicação da fonte da informação contida em um enunciado ou do meio pelo qual essa informação foi obtida, este trabalho aborda a expressão de dois subtipos evidenciais no português brasileiro: a inferência, que marca um raciocínio assentado puramente no conhecimento do falante ou em evidências de natureza linguística; e a dedução, que marca um raciocínio embasado por evidências perceptuais. Para tanto, são analisadas ocorrências dos verbos inferir, deduzir, concluir, perceber, observar e ver, extraídas do Corpus Brasileiro (SARDINHA; MOREIRA FILHO; ALAMBERT, 2010) e do Timestamped JSI web corpus 2014-2020 Portuguese (TRAMPUS; NOVAK, 2012).

Analisam-se usos dos verbos mencionados em orações complexas, como núcleo de orações matrizes, com o objetivo de descrever a combinação de tempo e modo entre a oração que contém o evidencial e a oração com a informação inferida ou deduzida. Tendo em vista que, nas relações de encaixamento, entende-se que o tipo do predicado

2 No original: "evidentiality strategies". 
encaixador determina a natureza semântica da unidade nele encaixada (DIK, 1997; HENGEVELD; MACKENZIE, 2008; entre outros), espera-se encontrar divergências no modo como orações com os verbos selecionados combinam-se com as categorias de tempo e modo, a depender do tipo de evidencialidade que expressam.

As análises deste estudo são embasadas pela classificação da evidencialidade proposta por Hengeveld e Hattnher (2015) e pela Gramática Discursivo-Funcional (HENGEVELD; MACKENZIE, 2008), doravante GDF. A categorização dos dados tem suas variáveis cruzadas pelo Goldvarb X (SANKOFF; TAGLIAMONTE; SMITH, 2005), cujos resultados são ponto de partida para a argumentação feita adiante.

Os dados presentes neste trabalho são parte dos achados obtidos por Silva (2020a), apresentados sob a forma de dissertação de mestrado, intitulada A expressão lexical da dedução e da inferência em língua portuguesa: uma análise discursivo-funcional, que se debruça sobre aspectos semânticos e morfossintáticos da expressão da inferência e da dedução no português brasileiro.

Este artigo está estruturado da seguinte maneira: em primeiro lugar, é feita uma breve explicação da teoria que embasa este estudo, e são apresentados, na perspectiva dessa teoria, os subtipos evidenciais analisados; em segundo lugar, explora-se o universo de dados utilizados, abordando-se sua origem e os critérios de levantamento e de análise das ocorrências; em terceiro lugar, são realizadas a análise dos dados e a discussão dos resultados obtidos; por fım, faz-se as considerações fınais desta pesquisa.

\section{Fundamentação teórica}

\section{A Gramática Discursivo-Funcional}

A Gramática Discursivo-Funcional (HENGEVELD; MACKENZIE, 2008) é uma teoria gramatical que concebe o enunciado como estratificado em níveis e camadas hierárquicos, em que as operações de formulação dos níveis Interpessoal e Representacional (da pragmática e da semântica, respectivamente) determinam as operações de codificação dos níveis Morfossintático e Fonológico. A GDF é entendida como o Componente Gramatical de um modelo maior de interação verbal, em que se relacionam o Componente Cognitivo, de onde partem as ideias e as intenções do falante, o Componente Contextual, que armazena informações contextuais importantes para a interação, e o Componente de Saída, responsável pela expressão, na fala, na escrita ou na gestualidade, da informação linguística produzida no Componente Gramatical.

Os componentes e as formulações linguísticas mencionados estão esquematizados na figura a seguir: 
Figura 1. A GDF como parte de uma teoria mais ampla da interação verbal

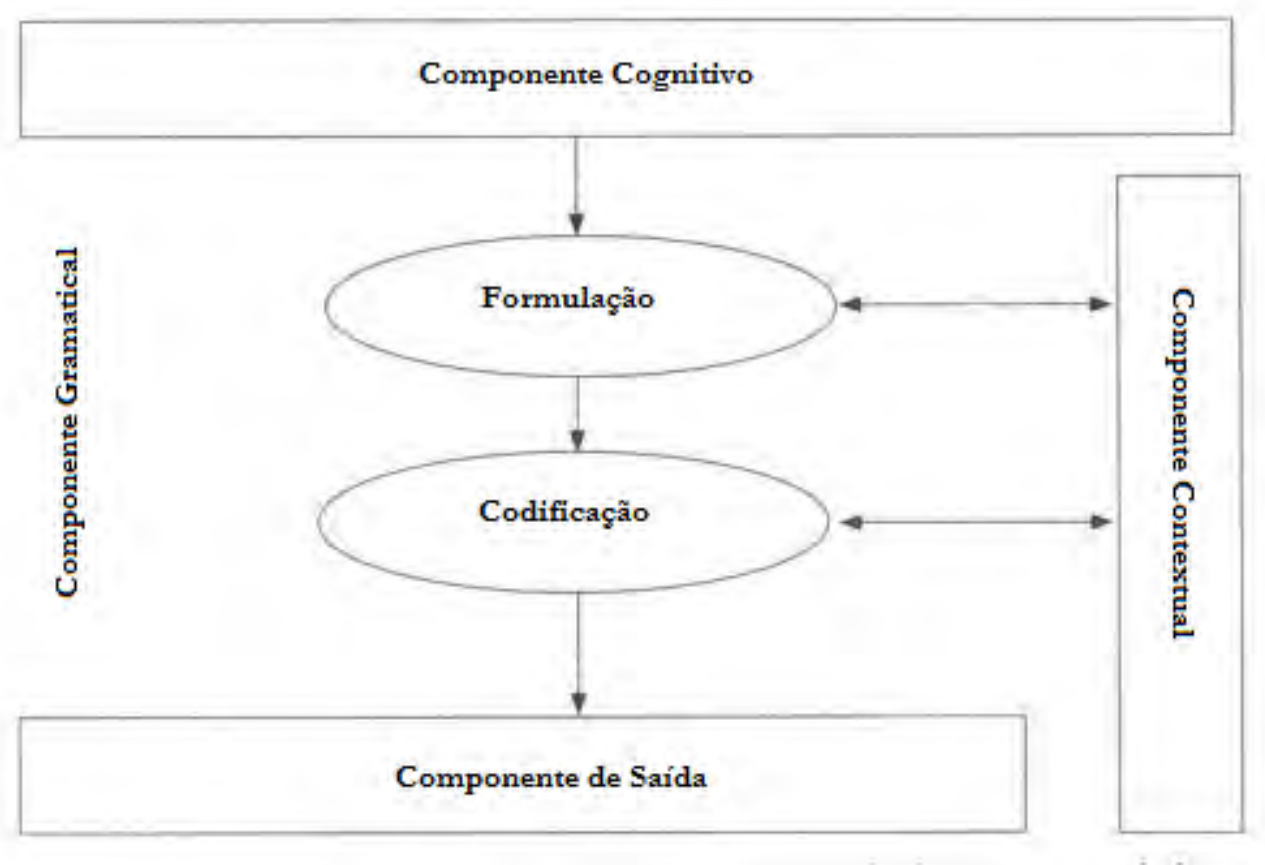

Fonte: Hengeveld e Mackenzie (2012, p. 44)

Para a discussão que segue, interessam as camadas do Nível Representacional. A mais alta na hierarquia é a do Conteúdo Proposicional, a qual diz respeito a um construto mental que não pode ser localizado no tempo nem no espaço. A segunda na hierarquia é a camada do Episódio, que consiste em um ou mais Estados de Coisas organizados em uma sequência de Tempo, Espaço, Participantes e domínio de Realidade. A terceira mais alta na hierarquia é a camada do Estado de Coisas, que diz respeito a um evento que pode ser localizado no tempo e no espaço. A quarta na hierarquia é a camada da Propriedade Configuracional, que corresponde aos moldes de predicação das línguas naturais. Essa última é formada por uma relação de camadas que não mantêm uma hierarquia entre si e que, não sendo relevantes para a discussão das próximas seções, não serão abordadas em detalhes neste artigo.

\section{A inferência e a dedução}

Para a GDF, a evidencialidade e outras categorias qualificacionais podem ser definidas a partir de seu escopo sobre as camadas e os níveis de estruturação do enunciado. Utilizando essa teoria linguística como suporte teórico e partindo da análise de 64 línguas indígenas brasileiras, Hengeveld e Hattnher (2015) propõem o reconhecimento de quatro subtipos evidenciais, entre eles a inferência e a dedução, que são tema desta investigação. 
De acordo com Hengeveld e Hattnher (2015, p. 485, tradução nossa³), o evidencial de inferência é utilizado pelo falante "para indicar que infere certa porção de informação com base em seu próprio conhecimento existente". Ainda segundo os autores, esse subtipo evidencial tem escopo sobre a camada do Conteúdo Proposicional. Um exemplo de marca evidencial de inferência em português pode ser visto em (2):

2. O mundo do futebol requer equilíbrio. Um dia estamos no topo, no outro estamos em baixa. Sinto que fiz a escolha certa em voltar para o Brasil e também em vir para o Botafogo. Gostava de viver lá, tive outras propostas até mesmo no Brasil, mas senti que aqui poderia ser minha nova casa. (VENDRAME, 2010, p. 145, grifos nossos).

Nesse exemplo, a partir de suas impressões, o falante infere que fez a escolha certa ao voltar para o Brasil e ingressar no time de futebol que o contratou. Nesse caso, como a base para o raciocínio são evidências internas ao falante, o verbo sentir funciona como a marca de uma inferência.

A dedução, por sua vez, que tem escopo sobre a camada do Episódio, é "utilizada para indicar que a informação apresentada pelo falante é deduzida com base em evidenciais perceptuais" (HENGEVELD; HATTNHER, 2015, p. 486, tradução nossa ${ }^{4}$ ). Uma ocorrência de marca evidencial de dedução em português é apresentada a seguir:

3. Ela entrou apressada, acendeu a luz da sala, sei, pelo barulho, que nem tirou os sapatos como é de costume aqui em casa. (KAPP-BARBOZA, 2017, p. 76, grifos da autora).

Em (3), a partir do barulho que ouve, o falante infere que a mulher de quem fala não tirou os sapatos quando entrou na casa. Tendo em vista que o raciocínio está assentado em uma percepção sensorial realizada por meio da audição, o verbo saber é utilizado como a marca de uma dedução.

Tanto a inferência quanto a dedução estão relacionadas ao modo de obtenção da informação, o qual diz respeito a um raciocínio, em ambos os casos. A diferença é o tipo de evidência que embasa esse raciocínio, já que a inferência não exige uma evidência perceptual, ao passo que a dedução exige. Além disso, com relação à inferência, uma evidência externa ao falante também pode sustentar o raciocínio marcado por esse subtipo evidencial, desde que essa evidência seja de natureza linguística. Isso porque,

3 No original: "[...] to indicate that he infers a certain piece of information on the basis of his/her own existing knowledge.".

4 No original: "[...] used to indicate that the information the speaker presents is deduced on the basis of perceptual evidence.". 
apesar de o estímulo físico que veicula a linguagem ser perceptível por meio da audição, no caso da fala, por meio da visão, no caso da escrita e da gestualidade, e por meio do tato, no caso do Tadoma ${ }^{5}$, esse estímulo precisa ser interpretado pelo processo cognitivo que nos permite compreender a linguagem. Desse modo, quando a evidência que sustenta um raciocínio é o conteúdo de um enunciado, a marca que expressa esse raciocínio é classificada como inferência. O exemplo (4) ilustra essa afırmação:

4. No dia seguinte soube que aquela cena havia sido exibida na TV. Entre o pessoal do DOI deve ter havido divergências sobre tal iniciativa. Deduzo isso pelo que comentou comigo um dos piores torturadores: "Eu fui contra. Não se deve dar nenhuma explicação sobre o que fazemos ou deixamos de fazer." (CB:Aca:Art).

Nessa ocorrência, a partir do dizer de outro indivíduo, o falante infere que houve divergências sobre a iniciativa de passar uma cena na televisão. A evidência que embasa o raciocínio, embora seja externa ao falante, é apreendida pela capacidade de interpretação da linguagem e, por isso, não caracteriza uma dedução. Desse modo, ocorrências como a apresentada em (4) são classificadas como inferência. Uma definição mais ampla desse subtipo evidencial, que engloba também casos como o mencionado anteriormente, é apresentada por Silva (2020a, p. 73-74), para quem "a inferência é utilizada para marcar uma informação proveniente de um raciocínio não assentado em evidências perceptuais, embasado puramente pelo conhecimento existente do falante ou também por evidências de natureza relatada".

Para contrastar, se o raciocínio tivesse sido embasado pelas características de articulação do som, e não pelo conteúdo linguístico da mensagem em si, esse raciocínio seria considerado uma dedução, como em (5):

5. Eu também percebo se estão com problema ou nervosos. Eu acho que a minha demonstração é na voz. Eu percebo isso na voz das pessoas, na forma de se expressar. Entre as colegas você sente pela voz quando elas estão tristes, muda totalmente. [...]. Então, eu vejo diferença: a voz alegre é mais clara, mais ativa; e a voz triste é para dentro, falta entusiasmo, é pausada. (CB:Aca:Art).

Nessa ocorrência, a partir de aspectos das vozes de suas colegas, a falante é capaz de deduzir o estado emocional dessas pessoas. A evidência que sustenta o raciocínio não é o conteúdo linguístico enunciado pelos indivíduos, mas as características de articulação do som. A obtenção da evidência, nesse caso, é realizada puramente pela audição, sem que seja necessária a interpretação linguística do que é falado, e, por essa razão, esse uso de perceber marca uma dedução.

5 Linguagem gestual utilizada por indivíduos surdo-cegos. 
Embora essa distinção possa ser menos evidente em português, que não dispõe de marcas especializadas para diferenciar a inferência e a dedução, ela é feita rigorosamente em outras línguas, como constatam Aikhenvald (2004), Kapp (2013), Hattnher (2013), Hengeveld e Hattnher (2015), entre muitos outros autores. Assim, em consonância com a teoria adotada, essa diferenciação é feita na análise dos dados.

\section{Universo de análise e critérios de trabalho com as ocorrências}

Como dito anteriormente, as funções reunidas sob o rótulo de evidencialidade são expressas lexicalmente no português brasileiro. Na pesquisa aqui descrita, essa categoria é analisada a partir do funcionamento de alguns verbos: três cognitivos, inferir, deduzir e concluir, que, entre outros sentidos, podem ser utilizados para indicar ações mentais; e três verbos de percepção, perceber, observar e ver, que costumam veicular percepções sensoriais, mas também expressam percepções mentais e cumprem outras funções.

A análise se dá sobre ocorrências representativas do português brasileiro contemporâneo e são retiradas do Corpus Brasileiro (SARDINHA; MOREIRA FILHO; ALAMBERT, 2010) e do Timestamped JSI web corpus 2014-2020 Portuguese (TRAMPUS; NOVAK, 2012), com o auxílio da ferramenta de gerenciamento de córpus Sketch Engine (KILGARRIFF et al., 2004).

Quando a ocorrência provém do Corpus Brasileiro, sua identificação ocorre da seguinte maneira: utiliza-se "CB" para indicar o Corpus Brasileiro; seguido de um gênero, o qual, nos exemplos apresentados adiante, pode ser Literatura (Lit), Academia (Aca) e Jornalismo (Jou); e, por fim, há a sigla da fonte, que pode ser Artigos (Art), Variados (Mis), Teses e dissertações (TaD) e Jornais (New). Quando a ocorrência provém do Timestamped JSI web corpus 2014-2020 Portuguese, por sua vez, usa-se a sigla "JSI" seguida do nome do domínio da internet no qual o texto foi originalmente publicado.

Para a busca de dados, quatro critérios são adotados, os quais consideram que o verbo: i) tem de apresentar o sentido de raciocínio; ii) deve estar na primeira pessoa do singular; iii) precisa estar no presente do indicativo; e iv) não pode estar sob o escopo da negação.

O primeiro critério considera a função da dedução e da inferência, que é expressar um raciocínio, e busca separar o uso evidencial inferencial e dedutivo desses verbos de seus outros usos. O segundo critério leva em conta a pessoa gramatical que tradicionalmente indica o falante, tido como responsável pelo raciocínio expresso pela estratégia de evidencialidade. 0 terceiro critério considera o recorte proposto por este trabalho, que é o de analisar apenas ocorrências no presente do indicativo dos verbos que veiculam a evidencialidade, e objetiva separar os usos nessa configuração dos outros usos presentes no córpus. Por fim, o quarto critério busca excluir ocorrências cujo sentido evidencial é bloqueado pela negação, uma vez que o verbo negado indica a não obtenção 
da informação pelo meio que esse verbo designa (como em "?pelo que vejo, não percebo que o rio é fundo $\left.{ }^{6 \prime}\right)$.

Embora se pretendesse trabalhar com 50 ocorrências de cada verbo, a quantidade de dados de dois deles, inferir e deduzir, após a aplicação dos critérios de seleção das ocorrências, ficou aquém do esperado. Assim, o número final de ocorrências levantadas é 277, na seguinte proporção: 37 ocorrências de inferir; 40, de deduzir; 50, de concluir; 50, de perceber; 50, de observar; e 50, de ver. Nesses números, estão inclusos todos os diferentes padrões morfossintáticos pelos quais são expressas a inferência e a dedução por meio dos verbos selecionados. No entanto, para a análise do presente trabalho, são consideradas somente as ocorrências na relação de complementação em que o complemento da matriz com o evidencial é uma oração finita, totalizando 216 ocorrências. A discussão sobre outros padrões morfossintáticos que expressam a inferência e a dedução por meio desses verbos (a justaposição, a modificação, a parentetização e mesmo a complementação em orações simples) pode ser encontrada em Silva (2020a, 2020b).

Além disso, para a discussão da próxima seção, os seguintes critérios de análise das ocorrências são propostos: i) verbo que veicula a inferência ou a dedução e sua respectiva classe verbal (cognitivo ou de percepção); ii) tipo de evidência que sustenta o raciocínio; iii) forma do elemento inferido ou deduzido; vi) relação morfossintática entre a oração evidencial e o elemento inferido ou deduzido; e v) tempo e modo da oração com a informação inferida ou deduzida.

O primeiro critério serve para identificar o verbo empregado pelo falante para veicular a inferência ou a dedução e classificá-lo como verbo de percepção ou verbo cognitivo, no intuito de verificar se há funcionamentos motivados pelo próprio lexema e/ou pela classe desses verbos. O segundo critério busca identificar uma ocorrência como inferência ou dedução a partir da base utilizada no raciocínio, já que, de antemão, esse é o único meio de diferenciá-las. Além disso, tendo em vista que a análise apresentada adiante se dá especificamente sobre a inferência e a dedução expressas por complementação, o terceiro e o quarto critérios são utilizados para identificar essa configuração morfossintática no universo dos dados analisados. O quinto critério, por fım, objetiva sistematizar a combinação de tempo e modo entre a oração matriz com o evidencial e a oração completiva com a informação inferida ou deduzida.

Após a classificação manual das ocorrências com os critérios mencionados anteriormente, o programa Goldvarb X (SANKOFF; TAGLIAMONTE; SMITH, 2005) foi utilizado para o cruzamento das variáveis atribuídas a partir desses critérios. A análise desse cruzamento é apresentada na seção seguinte.

60 ponto de interrogação indica que o enunciado é não natural. 


\section{Análise e discussão dos dados}

Como dito anteriormente, é o tipo do predicado encaixador que determina a unidade semântica da completiva (DIK, 1997; HENGEVELD; MACKENZIE, 2008). Assim, assumese que uma oração que contém a inferência deve encaixar um Conteúdo Proposicional e que uma oração que contém uma dedução deve encaixar um Episódio, já que são essas as camadas semânticas em que os subtipos evidenciais mencionados atuam. Como consequência, espera-se que, a depender do tipo de evidencialidade expresso na matriz, haja restrições nas qualificações presentes na completiva, tendo em vista que unidades semânticas distintas permitem combinações semânticas diferentes.

Nas línguas em que a evidencialidade, a modalidade e o tempo são expressos gramaticalmente, essas categorias costumam estar fortemente relacionadas e, em alguns casos, podem estar até mesmo sobrepostas (DIXON; AIKHENVALD, 1998; HATTNHER, 2013; KAPP, 2013; HENGEVELD; HATTNHER, 2015; AIKHENVALD, 2015; entre outros). Nesse sentido, este trabalho também objetiva verificar se se encontram as mesmas interações quando a evidencialidade é expressa lexicalmente, como acontece no português.

A começar pela dedução, a combinação de tempo e modo com esse subtipo evidencial é menor do que aquela encontrada com a inferência. Nos dados analisados, há ocorrências do verbo da oração completiva apenas em tempos do presente e do passado do modo indicativo. Um exemplo do uso do presente do indicativo é visto a seguir:

6. Percebo que o senhor é um entusiasta da sua linha de pensamento, como sou da minha disse ele. - Observo pelo seu indicador que o senhor faz os seus próprios cigarros. (JSI:uol).

Em (6), a partir de vestígios que observa no indicador de seu interlocutor, o falante deduz que o outro produz os próprios cigarros. Tendo em vista que a evidência em que está assentado o raciocínio é percebida pela visão, esse uso do verbo observar marca uma dedução.

O pretérito perfeito do indicativo também é encontrado na oração completiva que contém a informação deduzida, como a seguir:

7. Vejo cinza na sua camisa e no lençol... E o senhor cheirando a sarro de cigarro. Desculpe o sherlockismo, mas [pelo] seu hálito deduzo também que andou bebendo. (CB:Lit:Mis).

Nessa ocorrência, a partir do hálito que sente, o falante deduz que seu interlocutor esteve bebendo. Já que o raciocínio está assentado em uma evidência percebida por meio do olfato, o uso do verbo deduzir marca uma dedução. 
Outro tempo do passado encontrado na oração com a informação deduzida é o pretérito imperfeito do indicativo, como se observa em (8):

8. Passado o vão sob o MASP e chegando à área aberta que dá vista à Avenida Nove de Julho, logo atrás da cabine onde visitantes estrangeiros compram seus ingressos, noto o primeiro contraste: Pensei imediatamente que se tratava de uma pessoa morta, mas ao reparar que o tecido se mexia, concluo que, na realidade, esse era o leito de um morador de rua. (JSl:brasilpost).

Em (8), o falante avista uma pessoa que ele pensa estar morta, mas, ao observar que o cobertor se mexe, deduz que está viva e que lá se encontra porque é um morador de rua. O percurso completo do raciocínio pode ser entendido como "acho que está morto vejo o cobertor mexer-se - deduzo que está vivo - porque está ao relento, deduzo que é morador de rua - esse é o leito de um morador de rua". Ainda que haja um encurtamento da informação, no sentido de que apenas a caracterização como morador de rua é expressa linguisticamente, todo o raciocínio é sustentado por uma percepção visual, o que faz desse uso do verbo concluir uma estratégia para veicular a dedução.

No que diz respeito à inferência, no conjunto de dados analisado, são encontrados diferentes tempos e modos na oração completiva com a informação inferida. O primeiro exemplo é do presente do indicativo:

9. Pelo primeiro trecho, se nota que o local/estabelecimento da ação muda. Antes, se "tirava" a criança da rua para depois devolvê-la. Agora, tenta-se mudar o lugar onde ela está. Ainda por esse trecho, se percebe a representação sobre esse lugar: a rua tem violência, criminalidade, roubo, latrocínio, homicídio. Infiro que isso é uma conotação negativa da rua. (CB:Aca:TaD).

Nessa ocorrência, a partir da caracterização da rua que observa em um texto, o falante infere que essa representação é uma conotação negativa do espaço. Tendo em vista que o raciocínio é embasado por um conteúdo linguístico, o verbo inferir é empregado para sinalizar uma inferência.

O pretérito perfeito simples do indicativo e o pretérito perfeito composto do indicativo também são utilizados para situar a informação inferida pelo falante, como se observa, respectivamente, em (10) e (11):

10. Morreu de causas desconhecidas, mas deduzo que foi de tuberculose. Havia uma endemia de tísica na época em Londres e muitos padeceram. (CB:Jou:New). 
Nesse exemplo, a partir do conhecimento de que havia uma endemia de tuberculose na época do falecimento de uma pessoa, o falante infere que a morte aconteceu por causa da doença. Já que o raciocínio é embasado puramente por um conhecimento, o uso do verbo deduzir caracteriza uma inferência.

11. Mas hoje os pais procuram o psicólogo como se fosse ao médico, ao dentista, então, com certeza, há uma preocupação maior. Nesses anos todos, vejo que hoje em dia os pais têm nos buscado mais. (JSI:rdnews).

Em (11), a partir de sua experiência pessoal, o falante infere que atualmente os pais de crianças têm buscado mais os psicólogos do que antigamente. Como o raciocínio está assentado em evidências internas ao falante, o verbo ver marca uma inferência.

Ainda com relação a acontecimentos do passado, a marca do raciocínio inferencial é encontrada com o pretérito imperfeito (12), com o futuro do pretérito simples (13) e com o futuro do pretérito composto (14):

12. Acho oportuno dizer que fiz várias tentativas de localizar as vítimas dos processos analisados, mas não as encontrei. Deduzo que pelo fato de serem pessoas de baixa renda, moravam em casa alugada e nessas condições, mudam-se frequentemente. (CB:Aca:TaD).

Nesse exemplo, a partir da informação de que as vítimas do processo analisado eram pessoas de baixa renda, o falante deduz que suas casas eram alugadas, o que justificaria mudarem-se com frequência. A base para o raciocínio é o conhecimento do falante, o que caracteriza uma inferência.

13. Depois disso não sei o que eu poderia fazer lá, nem eles sabem. Não me deram perspectiva, então deduzo que, daqui a um tempo, eles iriam me tirar do programa. (CB:Jou:New).

Em (13), por não the terem dado perspectiva, o falante deduz que seria tirado de um programa. Tendo em vista que o raciocínio é baseado nas impressões dele e em seu conhecimento de mundo, o uso do verbo deduzir marca uma inferência.

14. Ao terminar este trabalho, vejo que alguns pontos poderiam ter sido diferentes. (CB:Aca:TaD).

Nessa ocorrência, ao reler seu trabalho, a falante infere que alguns pontos poderiam ter sido diferentes porque ela tinha condições de realizá-lo de outra maneira. Sendo a base do raciocínio um conhecimento, o uso de ver é classificado como inferência. 
Diferentemente da dedução, cujo fruto do raciocínio não é encontrado em tempos do futuro nos dados analisados, a oração com a informação inferida pode ser vista no futuro do presente, como a seguir:

15. Mais uma obra de Trump. Por isso, infiro que, antes que ele quebre o sistema americano e a pax americana, serão a pax americana e o sistema americano a quebrá-lo. (JSI:uol).

Nesse exemplo, com base em seu conhecimento de mundo, o falante infere que um indivíduo será "quebrado" pela pax americana e pelo sistema americano antes que ele os "quebre". O raciocínio é embasado puramente pelo conhecimento do falante, o que caracteriza o uso do verbo inferir como uma inferência.

Mais um contraste com a dedução é que, no caso da inferência, a completiva não está restrita ao modo indicativo. Nos dados analisados, são encontradas ocorrências em que o verbo da oração com a informação inferida está no presente do subjuntivo (16) e no pretérito perfeito do subjuntivo (17):

16. Depois de comer, ela observa que os bebês parecem mais calmos. "Eu deduzo que eles pensem assim: 'agora vamos descansar"', brincou. (JSI:midianews).

Nessa ocorrência, a falante infere um possível pensamento de seus bebês quando eles aparentam estar mais calmos. O raciocínio é meramente especulativo, baseado no conhecimento de mundo da falante, o que faz o verbo deduzir uma marca de inferência.

17. Outras áreas ao longo da fronteira de Hatay são controladas pela Frente al-Nusra, ligada à al-Qaeda. - Deduzo que eles tenham ido para Tel Abyad, porque sei que o hospital lá é extremamente ativo - disse o parlamentar. (JSI:globo).

Em (17), com base no conhecimento de que há um hospital ativo próximo a Tel Abyad, o falante infere que um grupo de pessoas foi para esse lugar. O raciocínio é embasado apenas por esse conhecimento, caracterizando uma inferência.

Por fım, a oração com a informação inferida também é encontrada no modo condicional. Esse valor modal é reconhecido nos casos em que a forma do futuro do pretérito é utilizada, mas a descrição não apresenta uma leitura temporal (CASTILHO, 2010), como a seguir:

18. Pelo exposto na reportagem do "Estadão" de ontem ("Lula usa cobertura em São Bernardo que foi comprada por primo de Bumlai"), concluo que, se não é a ajuda dos amigos e do povo brasileiro, o sr. Lula seria morador de rua, talvez mais um sem-teto. (JSI:estadao). 
Nessa ocorrência, com base na leitura de uma reportagem, o falante infere uma situação hipotética em que um indivíduo seria morador de rua. Como o raciocínio está embasado por uma evidência de natureza linguística, o uso do verbo concluir marca uma inferência.

A título de sumarização, as possibilidades de tempo e modo encontradas na oração com a informação inferida ou deduzida são apresentadas no quadro a seguir:

Quadro 1. Tempo e modo da Oração encaixada na Oração matriz com o evidencial

\begin{tabular}{|l|c|c|}
\hline \multirow{2}{*}{ Tempo e modo da oração encaixada } & \multicolumn{2}{|c|}{ Subtipo evidencial } \\
\cline { 2 - 3 } & Inferência & Dedução \\
\hline Presente do indicativo & + & + \\
\hline Pretérito perfeito simples do indicativo & + & + \\
\hline Pretérito perfeito composto do indicativo & + & + \\
\hline Pretérito imperfeito do indicativo & + & - \\
\hline Futuro do pretérito simples do indicativo & + & - \\
\hline Futuro do pretérito composto do indicativo & + & - \\
\hline Futuro do presente simples do indicativo & + & - \\
\hline Presente do subjuntivo & + & - \\
\hline Pretérito perfeito do subjuntivo & + & - \\
\hline Condicional & + & - \\
\hline
\end{tabular}

Fonte: Adaptado de Silva (2020a, p. 116).

Nesse quadro, o símbolo "+" representa a presença, e o "-", a ausência. Um primeiro ponto a ser destacado é a restrição da completiva com a informação deduzida ao modo indicativo, ao passo que a completiva com a informação inferida aparece também com os modos subjuntivo e condicional. Um segundo ponto a ser destacado é a restrição da informação deduzida a tempos do presente e do passado, enquanto a informação inferida é encontrada ainda com o futuro.

A começar pelo modo, a diferença observada na combinação dessa categoria com a inferência e com a dedução parece ser decorrente do tipo de entidade semântica sob a qual esses evidenciais têm escopo. Para iniciar essa discussão, é preciso antes retomar a definição da camada do Episódio e de aspectos da dedução.

Hengeveld, Fischer e Grandis (2018), ao estudar a condicionalidade no A'ingae, língua indígena falada no Equador e na Colômbia, observam que o uso de um elemento condicional introduz um novo Episódio, não por uma mudança de tempo absoluto, mas 
por uma mudança de domínio de Realidade. É por essa razão que Hengeveld, Fischer e Grandis (2018, p. 61, tradução nossa7, grifos dos autores) sugerem atualizar a definição de Episódio tal como apresentada por Hengeveld e Mackenzie (2008), reformulando-a como "um ou mais Estados de Coisas que são tematicamente coerentes, no sentido de que mostram unidade ou continuidade de Tempo, Lugar, Participantes e domínio de Realidade".

A inclusão do domínio de Realidade na definição do Episódio, segundo Hengeveld, Fischer e Grandis (2018), está de acordo com a proposta de se entender a modalidade objetiva epistêmica ${ }^{8}$ (e a distinção realis/irrealis, por conseguinte) como atuante nessa camada do Nível Representacional. Isso é especialmente relevante para a discussão aqui proposta porque uma das maneiras de se marcar a distinção realis/irrealis em português é por meio da alternância entre o indicativo e o subjuntivo, que, como visto ao longo desta seção, se combinam diferentemente com os subtipos evidenciais analisados.

Ao apresentar a dedução, Hengeveld e Hattnher (2015, p. 486, tradução nossa9) afırmam que ela "necessariamente envolve pelo menos dois estados-de-coisas relacionados: o percebido e o deduzido". O primeiro sempre é anterior ao segundo, na medida em que a realização do raciocínio depende de uma percepção sensorial feita previamente. Por esse motivo, entende-se que um evento é relativo ao outro, estando ambos em um mesmo Episódio. Tendo em vista que a percepção e o evento deduzido têm de estar em um mesmo domínio de Realidade para que figurem em um único Episódio, o uso do subjuntivo parece não ser verificado na completiva com o fruto da dedução porque isso sinalizaria uma mudança de domínio de Realidade. Como se vê no exemplo (6), retomado em (19) adiante, e na modificação proposta em (19a), o uso do subjuntivo nesse enunciado não é possível:

19. Observo pelo seu indicador que o senhor faz os seus próprios cigarros.

19a. *Observo pelo seu indicador que o senhor faça os seus próprios cigarros.

O mesmo argumento pode ser utilizado para justificar por que o condicional não é encontrado nas ocorrências de dedução analisadas, já que o uso desse modo implicaria uma diferença de domínio de Realidade entre a percepção que embasa o raciocínio e o evento deduzido, descaracterizando assim o Episódio em que atua a dedução.

7 No original: "One or more States-of-Affairs that are thematically coherent, in the sense that they show unity or continuity of Time, Location, Participants and Reality domain.".

8 Em consonância com Hengeveld (2011), este trabalho entende que a modalidade epistêmica objetiva é utilizada para caracterizar a (im)possibilidade de ocorrência de um Episódio a partir do que o falante sabe sobre o mundo.

9 No original: "[...] necessarily involves at least two related states-of-affairs: the perceived one and the deduced one.". 
Esse aspecto parece ser relevante até mesmo na classe de verbos que geralmente expressa os raciocínios embasados por evidências perceptuais. Nos dados analisados, os verbos de percepção representam $80,76 \%$ do total das ocorrências ${ }^{10}$, o que sugere que a semântica da dedução seleciona lexemas mais ligados a percepções sensoriais, as quais embasam esse tipo de raciocínio. Como consequência, a restrição ao modo indicativo é naturalmente imposta pelos verbos de percepção, que, de acordo com Santana (2010), encaixam preferencialmente orações completivas no indicativo.

Por sua vez, a unidade semântica sob a qual a inferência tem escopo, o Conteúdo Proposicional, ocupa uma posição mais alta do que o Episódio na hierarquia do Nível Representacional e, por isso, não é afetada pelas restrições de domínio de Realidade. Portanto, o fruto do raciocínio não precisa ser situado no mesmo domínio de Realidade de outro evento, como acontece com o resultado da dedução, e a oração com a informação inferida pode aparecer nos modos indicativo, subjuntivo e condicional. Além disso, diferentemente da dedução, a inferência não apresenta distinção relevante com relação à classe de verbos que a expressa, já que os verbos cognitivos constituem 52,18\% (120 usos) das ocorrências analisadas e os verbos de percepção, 47,82\% (110 usos). Essa distribuição equilibrada contribui para o aparecimento do subjuntivo, que, embora tenha seu uso restrito com os verbos de percepção, não encontra as mesmas barreiras com os verbos cognitivos.

No que concerne à combinação de tempo com os subtipos evidenciais analisados, a diferença no comportamento da inferência e da dedução parece decorrer, mais uma vez, da semântica desses evidenciais. Como dito anteriormente, a oração completiva com a informação deduzida é encontrada apenas em tempos do presente e do passado nos dados analisados. Resultado semelhante é obtido por Hattnher (2013) e por Kapp (2013), que, ao estudar a relação entre evidencialidade e tempo em línguas nativas do Brasil, verificam que, na maior parte das línguas analisadas, a dedução é utilizada apenas para descrever eventos no passado e, com menos frequência, há línguas que permitem o uso desse subtipo evidencial também com o presente.

Aikhenvald (2004, p. 174, tradução nossa ${ }^{11}$ ), ao discorrer sobre a complexidade semântica dos evidenciais de raciocínio, afirma que "dois tipos básicos de inferência podem adquirir expressão gramatical em sistemas evidenciais amplos: inferência baseada em resultados e conjectura baseada em raciocínio". O primeiro tipo corresponde ao que neste trabalho é chamado de dedução, e o segundo tipo corresponde à inferência. Por motivos lógicos, só pode haver resultados de eventos que tenham acontecido no passado ou que estejam

10 As porcentagens desta seção consideram as 277 ocorrências totais da pesquisa e não apenas as 216 da relação de complementação.

11 No original: "Two basic kinds of inference can acquire grammatical expression in large evidentiality systems: inference based on results and assumption based on reasoning.". 
acontecendo no presente. De um evento futuro, pode-se perceber um prenúncio, mas não um resultado. Portanto, parece haver pouca compatibilidade semântica entre a dedução expressa pelos verbos analisados e o futuro.

Com isso em mente, é possível levantar a hipótese de que o falante, para exprimir deduções baseadas não em resultados, mas em prenúncios, dê preferência a mecanismos que, ao mesmo tempo, expressem um raciocínio e relativizem o valor de verdade do enunciado, como os verbos achar e parecer nas ocorrências a seguir, retiradas da internet:

20. Que calor! Acho que vai chover. (internet).

21. Quando o sol vai sair de manhã, ele sai por trás de uma nuvem baixa e escura. Se sai embarrado, como nós chamamos, a gente sabe que vai chover. Tem a barra de 18 de outubro, barra de Natal, de Ano Novo. Tem também a técnica da lua. Se ela sai no nascente, é uma coisa linda, parece que vai chover. (internet ${ }^{12}$ ).

Em (20), a partir do calor que sente por meio do tato, o falante supõe que vai chover. Em (21), a partir da posição do céu em que a lua nasce, percebida por meio da visão, o falante chega à conclusão de que vai chover. Em ambos os casos, os verbos utilizados são elementos que expressam tanto a fonte da informação do enunciado quanto uma dúvida do falante (FREITAG, 2003). Como consequência, podem relativizar o valor de verdade do enunciado e proteger a face do falante ao comunicar conclusões sobre eventos futuros. Comprovar essa hipótese, no entanto, foge do escopo deste trabalho, e fica a cargo de pesquisas posteriores investigar a relação entre raciocínios/suposições acerca de eventos futuros e o uso de verbos que concomitantemente marcam um raciocínio e relativizam o valor de verdade do enunciado.

Por fim, é preciso destacar que a realização do raciocínio marcado pela inferência não exige nenhuma evidência externa ao conhecimento do falante e, portanto, não está "ancorada" em resultados, como costuma estar a dedução. Assim, ainda que sejam menos frequentes, eventos futuros também são marcados como o resultado de um raciocínio inferencial pelos verbos analisados.

\section{Considerações finais}

Este trabalho teve como objetivo descrever combinações de tempo e modo com os subtipos evidenciais de inferência e dedução no português brasileiro, expressos por meio de verbos cognitivos e de verbos de percepção. Analisando mais especificamente orações complexas na relação morfossintática de complementação, em que a matriz expressa um dos subtipos evidenciais citados e em que a completiva contém o fruto

12 Disponível em: https://bit.ly/3m3IVpU. 
do raciocínio, foi possível verificar que, a depender do subtipo evidencial veiculado pelo predicado encaixador, as possibilidades de combinação de tempo e modo da oração completiva são diferentes.

Em primeiro lugar, quando os verbos inferir, deduzir, concluir, perceber, observar e ver são utilizados para marcar uma dedução, o evento deduzido é posto em tempos do presente e do passado do modo indicativo. A não ocorrência do futuro com a dedução parece decorrer da pouca compatibilidade semântica entre ambos, já que o raciocínio dedutivo costuma ser realizado a partir de resultados de um evento, e não de seus prenúncios. Como hipótese a ser comprovada ou refutada posteriormente, supõe-se que, para falar sobre deduções de eventos futuros, o falante dê preferência a lexemas que, ao mesmo tempo, marquem um raciocínio e relativizem o valor de verdade do enunciado, protegendo, assim, sua face. Além disso, a restrição dos eventos deduzidos ao modo indicativo parece ser um reflexo do pertencimento, a um mesmo domínio de Realidade, do evento deduzido e da percepção que o embasa.

Em segundo lugar, no que diz respeito à combinação de tempo e modo com a inferência, o fruto desse raciocínio é encontrado, nos dados analisados, com tempos do presente, do passado e do futuro e com os modos indicativo, subjuntivo e condicional. Tendo em vista que o tipo de raciocínio marcado pela inferência pode ser meramente especulativo, sem o embasamento de uma evidência externa ao conhecimento do falante, a falta de uma "ancoragem" em outro evento, como há na dedução, possibilita que haja mais combinações modais e temporais com esse subtipo evidencial do que com o outro.

Por fim, à guisa de conclusão, este trabalho demonstrou que as divergências na combinação de tempo e modo entre a inferência e a dedução podem ser explicadas como decorrentes da semântica desses subtipos evidenciais e das unidades semânticas sob as quais eles têm escopo, o Conteúdo Proposicional e o Episódio, respectivamente. Nesse sentido, ainda que os itens que marquem a inferência e a dedução sejam polissêmicos e sirvam à expressão de ambos os subtipos, é possível identificar diferenças semânticas que justifiquem separá-las, mesmo em uma língua como o português, que não as marca gramaticalmente.

\section{Agradecimentos}

O presente trabalho foi realizado com apoio da Coordenação de Aperfeiçoamento de Pessoal de Nível Superior - Brasil (CAPES) - Código de Financiamento 001, a quem agradeço. 


\section{REFERÊNCIAS}

AIKHENVALD, A. Y. Evidentials: Their links with other grammatical categories. Linguistic Typology, v. 19, n. 2, p. 239-277, 2015.

AIKHENVALD, A. Y. Evidentiality. Oxford: Oxford University Press, 2004.

AIKHENVALD, A. Y.; DIXON, R. M. W. Dependencies between Grammatical Systems. Language, v. 74, n. 1, p. 56-80, mar. 1998.

CASTILHO, A. T. de. Nova Gramática do Português Brasileiro. São Paulo: Editora Contexto, 2010

DIK, S. C. The theory of Functional Grammar. Part II - Complex and derived constructions. Nova York: Mouton de Gruyter, 1997.

FREITAG, R. M. O papel da freqüência de uso na gramaticalização de acho (que) e parece (que) marcadores de dúvida na fala de Florianópolis. Veredas, v. 7, n. 1 e n. 2, p. 113-132, jul./dez. 2003.

HATTNHER, M. M. D. The interaction between tense and evidentials of event perception and deduction in Brazilian native languages. In: MACKENZIE, J. L.; OLBERTZ, H. (ed.). Casebook in Functional Discourse Grammar. Amsterdã: John Benjamins, 2013. p. 39-66.

HENGEVELD, K. The grammaticalization of tense and aspect. In: HEINE, B.; NARROG, H. (ed.). The Oxford Handbook of Grammaticalization. Oxford: Oxford University Press, 2011. p. 580-594.

HENGEVELD, K.; FISCHER, R.; GRANDIS, S. Episodes, New Topics and Conditionals in A'ingae. 2018. 70 slides. Disponível em: http://www.keeshengeveld.nl. Acesso em: 15 jan. 2019.

HENGEVELD, K.; HATTNHER, M. M. D. Four Types of Evidentiality in the Native Languages of Brazil. Linguistics, v. 53, n. 3, p. 479-524, 2015.

HENGEVELD, K.; MACKENZIE, L. Gramática Discursivo-Funcional. Tradução Marize Mattos Dall'Aglio-Hattnher. In: SOUZA, E. R. F. Funcionalismo linguístico: análise e descrição. São Paulo: Contexto, 2012. p. 43-85.

HENGEVELD, K.; MACKENZIE, L. Functional Discourse Grammar. A typologically-based theory of language structure. Oxford: Oxford University Press, 2008. 
KAPP, A. M. M. Relações entre tempo e evidencialidade nas línguas indígenas do Brasil: um estudo tipológico-funcional. 2013. Dissertação (Mestrado em Estudos Linguísticos) Instituto de Biociências, Letras e Ciências Exatas, Universidade Estadual Paulista "Júlio de Mesquita Filho", São José do Rio Preto, 2013.

KAPP-BARBOZA, A. M. M. Usos do verbo saber e a expressão da evidencialidade no português brasileiro. 2017. Tese (Doutorado em Estudos Linguísticos) - Instituto de Biociências, Letras e Ciências Exatas, Universidade Estadual Paulista "Júlio de Mesquita Filho", São José do Rio Preto, 2017.

KILGARRIFF, A.; RYCHLY, P.; SMRZ, P.; TUGWELL, D. Itri-04-08 The Sketch Engine. Information Technology, 2004.

SANKOFF, D.; TAGLIAMONTE, S. A.; SMITH, E. Goldvarb X: A variable rule application for Macintosh and Windows. Department of Linguistics, University of Toronto, 2005.

SANTANA, L. Relações de complementação no português brasileiro: uma perspectiva discursivo-funcional. São Paulo: Cultura Acadêmica, 2010.

SARDINHA, T. B.; MOREIRA FILHO, J. L.; ALAMBERT, E. Corpus Brasileiro. São Paulo: CEPRIL, LAEL, CNPq, FAPESP, PUCSP, 2010.

SILVA, V. H. S. A expressão lexical da dedução e da inferência em língua portuguesa: uma análise discursivo-funcional. 2020. Dissertação (Mestrado em Estudos Linguísticos) Instituto de Biociências, Letras e Ciências Exatas, Universidade Estadual Paulista "Júlio de Mesquita Filho", São José do Rio Preto, 2020a.

SILVA, V. H. S. Padrões morfossintáticos da inferência e da dedução em língua portuguesa. Estudos Linguísticos, v. 49, n. 1, p. 346-363, abr. 2020b.

TRAMPUS, M.; NOVAK, B. The Internals Of An Aggregated Web News Feed. In: Multiconference on Information Society, 15, 2012. Anais eletrônicos... Ljubljana (Slovenia): Jožef Stefan Institute, 2012. Disponível em: http://library.ijs.si/Stacks/ Proceedings/InformationSociety/2012/. Acesso em: 24 set. 2020.

VENDRAME, V. Os verbos ver, ouvir e sentir e a expressão da evidencialidade em língua portuguesa. 2010. Tese (Doutorado em Estudos Linguísticos) - Instituto de Biociências, Letras e Ciências Exatas, Universidade Estadual Paulista "Júlio de Mesquita Filho", São José do Rio Preto, 2010. 